Research Paper

\title{
Evaluation of Polymethine Dyes as Potential Probes for Near Infrared Fluorescence Imaging of Tumors: Part - I
}

\author{
Nadine S. James ${ }^{1}$, Yihui Chen ${ }^{1}$, Penny Joshi' ${ }^{1}$, Tymish Y. Ohulchanskyy ${ }^{2}$, Manivannan Ethirajan ${ }^{1}$, Maged \\ Henary $^{3}$, Lucjan Strekowsk ${ }^{3}$ and Ravindra K Pandey ${ }^{1 凶}$ \\ 1. Department of Molecular and Cellular Biophysics and Biochemistry, Cell Stress Biology, Roswell Park Cancer Institute, Buffalo, NY \\ 14263; \\ 2. Institute for Lasers, Photonics and Biophotonics, University at Buffalo, NY 14260. \\ 3. Department of Chemistry, Georgia State University, Atlanta GA 30302, USA.
}

$\square$ Corresponding author: Ravindra K. Pandey, Ph. D., PDT Center, Cell Stress Biology, Roswell Park Cancer Institute, Buffalo, NY 14263, Tel: 716-845-3203, Fax: 716-845-8920.

(C) Ivyspring International Publisher. This is an open-access article distributed under the terms of the Creative Commons License (http://creativecommons.org/ licenses/by-nc-nd/3.0/). Reproduction is permitted for personal, noncommercial use, provided that the article is in whole, unmodified, and properly cited.

Received: 2013.01.21; Accepted: 2013.03.15; Published: 2013.08.21

\begin{abstract}
Near-infrared (NIR) organic dyes have become important for many biomedical applications, including in vivo optical imaging. Conjugation of NIR fluorescent dyes to photosensitizing molecules (photosensitizers) holds strong potential for NIR fluorescence image guided photodynamic therapy (PDT) of cancer. Therefore, we were interested in investigating the photophysical properties, in vivo tumor-affinity and fluorescence imaging potential of a series of heterocyclic polymethine dyes, which could then be conjugated to certain PDT agents. For our present study, we selected a series of symmetrical polymethine dyes containing a variety of bis- $\mathrm{N}$-substituted indole or benzindole moieties linked by linear conjugation with and without a fused substituted cyclohexene ring. The $\mathrm{N}$-alkyl side chain at the $\mathrm{C}$-terminal position was functionalized with sulfonic, carboxylic acid, methyl ester or hydroxyl groups. Although, among the parent cyanine dyes investigated, the commercially available, cyanine dye IR783 (3) (bis-indole-N-butylsulfonate)-polymethine dye with a cyclic chloro-cyclohexene moiety showed best fluorescence-imaging ability, based on its spectral properties $\left(\lambda_{\mathrm{Abs}}=782 \mathrm{~nm}, \lambda_{\mathrm{Fl}}=810 \mathrm{~nm}, \varepsilon=\right.$ $261,000 \mathrm{M}^{-1} \mathrm{~cm}^{-1}, \Phi_{\mathrm{F} 1} \approx 0.08$ ) and tumor affinity. In addition to 3, parent dyes IR820 and Cypate (6) were also selected and subjected to further modifications by introducing desired functional groups, which could enable further conjugation of the cyanine dyes to an effective photosensitizer HPPH developed in our laboratory. The synthesis and biological studies (tumor-imaging and PDT) of the resulting bifunctional conjugates are discussed in succeeding paper (Part-2 of this study).
\end{abstract}

Key words: Photodynamic therapy, Near Infrared Fluorophores, Reactive Oxygen Species, Near Infrared Fluorescence Imaging, Fluorescence Quantum Yields.

\section{Introduction}

Over the past few years, NIR fluorescence imaging techniques have advanced considerably and as such are increasingly becoming important translational tools from bench side research, with the use of small animals, to clinical application [1-7]. It is being used in challenging applications [8], on the micro- scopic and macroscopic platform such as the in vivo imaging of biological targets and diseases [9]. Animal models of human cancer and metastasis have been developed to aid in the understanding of disease progression and development of treatment [10].

Fluorescent probes have been shown to facilitate 
in vivo characterization of tumors, significantly advancing tumor visualization $[4,11]$, enable detection and identification of small pre-neoplastic lesions, and metastasis [4]. In vivo fluorescence imaging is usually conducted within the "tissue transmission window" which corresponds to a near- infrared (NIR) spectral range of $700-900 \mathrm{~nm}$. For this spectral range, scattering of the excitation light and tissue autofluorescence is minimal, resulting in facilitated deep tissue imaging due to substantially increased signal/noise ratio [12]. A great number of polymethine cyanine-based fluorophores are being used as exogenous probes for NIR fluorescence imaging. These compounds usually are not tumor-avid (therefore, tumor targeting becomes essential). Their excitation/emission wavelengths can be tuned to the desired spectral range by altering the indolenine or benzindolenine heterocyclic nucleus and the number of double bonds in the polymethine chain [13]. Some of these cyanine dyes have sulfonate groups directly attached to the aromatic benzindolenium or indolenium nucleus. These groups shield the fluorophores from non-specific hydrophobic interaction with other molecules, a process known to affect the emission of many fluorophores in aqueous media [13]. Additionally, dyes containing sulfonate or sulfonatoalkyl groups attached to the heterocyclic nucleus, tend to aggregate less [14]. Various structural modifications have been made to the polymethine chromophores to enhance its light and chemical stability [14]. These modifications usually include rigidization of the polymethine chain in order to inhibit radiationless internal conversion (IC) and subsequent isomerization [14]. The stability of the polymethine chain is lowered as the chain lengthens. However, incorporation of a central ring system such as a cyclohexenyl group enhances the rigidity of the polymethine chain, decreases the efficiency of IC and increases the fluorescence quantum yield.

This screening was performed in order to select the optimal fluorophore(s) for the synthesis of molecule(s) (photosensitizer-near infrared fluorophore conjugate (PS-NIRF)), see the part 2 related article from the same author within this journal, that can be used as a single unit combining photodiagnosis, fluorescence guided resection and phototherapy [15]. Herein, we report results of the evaluation of several polymethine dyes as near-infrared fluorescence probes for tumor imaging in vivo.

\section{Materials and Methods}

In vitro studies: In vitro tumor cell uptake (Colon 26 and U87 cell lines).

Chemistry: All compounds used for the synthe- sis were purchased from Sigma Aldrich and used directly. The compounds were characterized by NMR spectroscopy, HRMS, and UV-Vis. Purification was done by flash column chromatography.

Formulation: For solubility in aqueous solution all dyes were formulated in 1\% DMSO/1\% Tween-80 in $\mathrm{D} 5 \mathrm{~W}$ for in vitro and in vivo studies and in MeOH:DMSO (99:1 v/v) for photophysical studies.

Photophysical characterization: UV-Vis absorption spectra of compounds ( $\mathrm{MeOH}$ solutions) were acquired using a Shimadzu UV-3600 spectrophotometer. The extinction coefficients of all compounds were determined by weighing a particular amount of solid and dissolving in a $50 \mathrm{ml}$ volumetric flask using methanol as the solvent. First, the molar concentration (C) of each solution was calculated from its weight and volume. The absorbance (A) obtained from the UV-Vis spectrophotometric measurements was used to determine the extinction coefficient $(\varepsilon)$ from Beer-Lambert's Law $(\mathrm{A}=\varepsilon d C)$, where $d$ is optical path length (cuvette thickness, $d=1 \mathrm{~cm}$ ) Fluorescence spectra were recorded using a Fluorolog-3 spectrofluorometer or a SPEX 270M Spectrometer (Jobin Yvon, Longjumeau, France). The SPEX 270M Spectrometer was utilized for measurements in NIR range; a $532 \mathrm{~nm}$ line from continuous wave solid state laser (Millenia, Spectra Physics) or laser diodes emitting at 630 and $785 \mathrm{~nm}$ were used as an excitation. Singlet oxygen, ${ }^{1} \mathrm{O}_{2}{ }^{*}$, generation was detected by its phosphorescence emission signal at $1270 \mathrm{~nm}$. A SPEX 270M Spectrometer equipped with Hamamatsu IR-PMT was used for recording singlet oxygen phosphorescence spectra. The sample placed in a quartz cuvette was positioned directly in front of the entrance slit of the spectrophotometer, and the emission signal was collected at $90^{\circ}$ relative to the excitation laser beam. Additional long-pass filters [a $950 \mathrm{LP}$ filter and a 538 AELP filter (both from Omega Optical)] were used to attenuate the scattered light and fluorescence from the samples. ${ }^{1} \mathrm{O}_{2}{ }^{*}$ phosphorescence decays at $1270 \mathrm{~nm}$ was acquired using Infinium oscilloscope (Hewlett-Packard) coupled to the output of the PMT. A second harmonic $(532 \mathrm{~nm})$ from a nanosecond pulsed Nd: YAG laser (Lotis TII, Belarus) operating at $20 \mathrm{~Hz}$ was used as the excitation source.

In vitro tumor models: Colon 26 cells were grown in sterile RPMI-1640, 1x with L-glutamine with $10 \%$ Fetal Calf Serum (FCS) (Atlanta Biologicals, triple $0.1 \mu \mathrm{m}$ filtered, Lawrenceville, GA), and $1 \%$ Penicillin/Steptomycin/L-glutamine (P/S/l-G 10,000 $\mathrm{I} . \mathrm{U} / \mathrm{ml}$ penicillin, $10,000 \mu \mathrm{g} / \mathrm{ml}$ streptomycin, 29.2 $\mathrm{mg} / \mathrm{ml} \mathrm{L}$-glutamine) was maintained in $5 \% \mathrm{CO}_{2}, 95$ $\%$ air and $100 \%$ humidity. U87, gliobastoma astrocytoma, cells were grown in Medium Essential Medium 
Eagle (MEM), 1x with Earle's Salt and L-glutamine, sterile with $10 \%$ FCS, $1 \% \mathrm{P} / \mathrm{S} / \mathrm{l}-\mathrm{G}, 1 \% \mathrm{MEM}$ Non-essential Amino Acids 100x solution, sterile, $1 \%$ Sodium Pyruvate, $100 \mathrm{mM}$ solution, sterile, and $1 \%$ $\mathrm{P} / \mathrm{S} / \mathrm{l}-\mathrm{G}$ and maintained in $5 \% \mathrm{CO}_{2}, 95 \%$ air and 100 $\%$ humidity. All reagents, except FCS, but including Trypsin/EDTA, 1x (0.25 \% Trypsin / 2.21 mM EDTA in HBSS without sodium bicarbonate, calcium and magnesium, sterile, Porcine Parvovirus tested) and DPBS, 1x (Dulbecco's Phosphate Buffered Saline), without calcium and magnesium, sterile were purchased from MediaTech, Inc., Manassas VA 20109. The 96 and 6 well plates were purchased from VWR.

Animal and tumor models: Prior to commencement of in vivo studies all procedures or protocols were approved by the institutional animal care committee (IACUC). BALB/c mice 5-8 weeks of age were obtained from NCI Jackson Laboratory. The mice were inoculated subcutaneously (S.C.) on the right posterior shoulder with Colon $26\left(1 \times 10^{6}\right.$ cells in $50 \mu \mathrm{l}$ medium) between 7-14 weeks of age.

Tumor imaging: Three BALB/c mice per group bearing Colon 26 were imaged at three time points 24 , 48 and $72 \mathrm{~h}$ after being anesthetized with Ketamine/Xylazine, delivered intraperitonally or anesthetized with isofluorane. Compounds were imaged using a Maestro GNIR Flex In-vivo imaging system using a broadband excitation at $710-740 \mathrm{~nm}$ and an 800 $\mathrm{nm}$ long pass emission.

Tumor uptake (in vitro): In vitro cell uptake was determined by flow cytometry using a modified Becton Dickinson FACScan with a single laser. Colon 26 and U87 cells were seeded at $5.0 \times 10^{5}$ in 6 well plates in $2 \mathrm{ml}$ complete media for $24 \mathrm{~h}$. The dyes were added at a concentration of $1 \mu \mathrm{M}$ and incubated in the dark at $37{ }^{\circ} \mathrm{C}$ for $24 \mathrm{~h}$. Cells in each well were harvested and placed in $5 \mathrm{ml}$ flow tubes with sieve caps, centrifuged cold at $4000 \mathrm{rpm}$ at $10{ }^{\circ} \mathrm{C}$ for 10 minutes. After removing the supernatant the cells were re-suspended in cold $300 \mu \mathrm{l} 2 \%$ FCS in PBS (FCM Buffer), placed on ice then analyzed. A single diode laser excitation at $785 \mathrm{~nm}$ was used (maximum power 40mw (currently at $17 \mathrm{mw}$ ). Emission was detected using $820 \mathrm{~nm}$ long pass (LP) filter. The data was plotted using Microsoft Excel after it was generated via FCS Express 4.0 as Microsoft power point slides.

2-((E)-2-((E)-2-chloro-3-((E)-2-(1-(2-hydroxyethy 1)-3,3-dimethylindolin-2-ylidene) ethylidene)cycloh ex-1-en-1-yl)vinyl)-1-(2-hydroxyethyl)-3,3-dimethyl3H-indol-1-ium bromide (1): It was prepared by following the methodology discussed by Strekowski et al [16-18]

Sodium-6-((E)-2-((E)-2-(3-((E)-2-(1-(5-carboxylat opentyl)-3,3-dimethyl3H-indol-1-ium-2-yl)vinyl)-2-c hlorocyclohex-2-en-1-ylidene)ethylidene)-3,3 dimet hylindolin-1-yl)hexanoate bromide (2): It was prepared by following the methodology discussed by Strekowski et al [16-18]

Sodium-4-((E)-2-((E)-2-(2-chloro-3-((E)-2-(3,3-di methyl-1-(4-sulfonato butyl)-3H-indol-1-ium-2-yl)vi nyl) cyclohex-2-en-1-ylidene)ethylidene)-3,3-dimeth ylindolin-1-yl)butane-1-sulfonate (3): It was prepared by following the methodology discussed by Strekowski et al [16-18]

Sodium-4-(2-((E)-2-((E)-2-((4-carboxyphenyl)thi o)-3-((E)-2-(1,1-dimethyl-3-(4-sulfonato butyl)-1H-be nzo[e]indol-2(3H)-ylidene)ethylidene)cyclohex-1-en -1-yl)vinyl)-1,1-dimethyl-1H-benzo[e]indol-3-ium-3yl)butane-1 sulfonate (5): In a dry $100 \mathrm{~mL}$ round bottom flask (rbf), IR 820 (100 mg, $0.11 \mathrm{mmol})$ and 4-mercaptobenzoic acid $(90 \mathrm{mg}, 0.58 \mathrm{mmol})$ were dissolved in dry DMF $(5 \mathrm{~mL})$ and stirred for $16 \mathrm{~h}$ at room temperature under Argon atm. DMF was removed under reduced pressure, the residue obtained was purified by silica gel column chromatography by eluting with $\mathrm{MeOH} / \mathrm{DCM}(1: 4)$ solvent system, and the desired product was obtained in $83 \%$ yield. UV-Vis $\lambda_{\max }$ (in MeOH): $835 \mathrm{~nm}(\varepsilon=1.96$ x $\left.10^{5} \mathrm{~cm}^{-1}\right) ;{ }^{1} \mathrm{H}$ NMR $\left(400 \mathrm{MHz}, \mathrm{CDCl}_{3}, \delta \mathrm{ppm}\right): 8.87$ (d, $2 \mathrm{H}, J=14 \mathrm{~Hz}), 8.15(\mathrm{~d}, 2 \mathrm{H}, J=14 \mathrm{~Hz}), 87.91-7.99(\mathrm{~m}$, $6 \mathrm{H}), 7.57-7.63(\mathrm{~m}, 4 \mathrm{H}), 7.44(\mathrm{t}, 2 \mathrm{H}, \mathrm{J}=7.2 \mathrm{~Hz}), 7.36(\mathrm{~d}$, $2 \mathrm{H}, J=8.4 \mathrm{~Hz}), 6.40(\mathrm{~d}, 2 \mathrm{H}, J=14 \mathrm{~Hz}), 4.27(\mathrm{t}, 4 \mathrm{H}, J=$ $7.6 \mathrm{~Hz}), 2.85-2.92(\mathrm{~m}, 8 \mathrm{H}), 1.93-2.10(\mathrm{~m}, 10 \mathrm{H}), 1.77$ (s, $12 \mathrm{H}) . \mathrm{m} / \mathrm{z}$ calculated for $[\mathrm{M}]^{+} \mathrm{C}_{53} \mathrm{H}_{56} \mathrm{~N}_{2} \mathrm{NaO}_{8} \mathrm{~S}_{3}$ : 966.3018, found HRMS (TOFMS) [MH] ${ }^{+}$967.3127; low res (ESIMS) $[\mathrm{M}+\mathrm{Na}]^{+}: 989.4$

Synthesis of the Near Infrared Fluorophore (Cypate) (6): It was prepared by following the procedure published by Samuel Achilefu et al $[19,20]$.

Sodium-4-(2-((E)-2-((E)-2-((3-carboxyphenyl)thi o)-3-((E)-2-(1,1-dimethyl-3-(4-sulfonatobutyl)-1H-be nzo[e]indol-2(3H)-ylidene)ethylidene)cyclohex-1-en -1-yl)vinyl)-1,1-dimethyl-1H-benzo[e]indol-3-ium-3yl)butane-1-sulfonate (7): In a dry $100 \mathrm{ml}$ round bottom flask (rbf), IR 820 (100 mg, $0.11 \mathrm{mmol})$ and 3-mercaptobenzoic acid (200 mg) was dissolved in dry DMF and stirred for $12-16 \mathrm{~h}$ at room temperature under Argon atm. After DMF was removed by high vacuum, the residue was purified by chromatography using $\mathrm{MeOH} / \mathrm{DCM}(1: 3)$ as the elute solvent and the product was obtained in $80 \%$ yield $(89 \mathrm{mg})$. UV-Vis $\lambda_{\max }$ (in $\left.\mathrm{MeOH}\right): 834 \mathrm{~nm}\left(\varepsilon=2.07 \times 10^{5} \mathrm{~cm}^{-1}\right) ;{ }^{1} \mathrm{H}$ NMR $\left(400 \mathrm{MHz}, \mathrm{CHCl}_{3}, \delta\right): 8.88(\mathrm{~d}, \mathrm{~J}=11.2 \mathrm{~Hz}, 2 \mathrm{H}, \mathrm{Ar}-\mathrm{H}$ of cyanine dye), $8.13(\mathrm{~m}, 2 \mathrm{H}$, Ar-H of cyanine dye), 7.94 $(\mathrm{t}, \mathrm{J}=8.5 \mathrm{~Hz}, 5 \mathrm{H}, 4 \mathrm{H}$ for Ar- $\mathrm{H}$ of cyanine dye, $1 \mathrm{H}$ for Ar-H of mercaptobenzoyl group), 7.59 (d, J=8.5Hz, $5 \mathrm{H}, 4 \mathrm{H}$ for $\mathrm{Ar}-\mathrm{H}$ of cyanine dye, $1 \mathrm{H}$ for $\mathrm{Ar}-\mathrm{H}$ of mercaptobenzoyl group), 7.43 (m, 4H, 2H for Ar-H of 
mercaptobenzoyl group, $2 \mathrm{H}$ for $-\mathrm{CH}=\mathrm{CH}-\mathrm{C}=\mathrm{C}-\mathrm{C}=$ $\mathrm{CH}-\mathrm{CH}=\mathrm{C}-), 6.36(\mathrm{~d}, \mathrm{~J}=12.9 \mathrm{~Hz}, 2 \mathrm{H},-\mathrm{CH}=\mathrm{CH}-\mathrm{C}=$ $\mathrm{C}-\mathrm{C}=\mathrm{CH}-\mathrm{CH}=\mathrm{C}-), 4.27\left(\mathrm{~m}, 4 \mathrm{H}, 2 \mathrm{X}-\mathrm{NCH}_{2}\left(\mathrm{CH}_{2}\right)_{3} \mathrm{SO}_{3}{ }^{-}\right)$, $2.90\left(\mathrm{~m}, 4 \mathrm{H}, 2 \mathrm{X}-\mathrm{N}\left(\mathrm{CH}_{2}\right)_{3} \mathrm{CH}_{2} \mathrm{SO}_{3}^{-}\right), 2.84(\mathrm{~m}, 4 \mathrm{H}$, $\left.2 \mathrm{X}-\mathrm{N}\left(\mathrm{CH}_{2}\right)_{2} \mathrm{CH}_{2} \mathrm{CH}_{2} \mathrm{SO}_{3}^{-}\right), 2.01 \quad(\mathrm{~m}, 10 \mathrm{H}, 6 \mathrm{H}$ for cyclohexene- $\left(\mathrm{CH}_{2}\right)_{3}, 4 \mathrm{H}$ for $2 \mathrm{X}-\mathrm{NCH}_{2} \mathrm{CH}_{2}\left(\mathrm{CH}_{2}\right)_{2} \mathrm{SO}_{3}^{-}{ }^{-}$, $1.75\left(\mathrm{~s}, 12 \mathrm{H}, 4 \mathrm{X}-\mathrm{CH}_{3}\right) . \mathrm{m} / \mathrm{z}$ calculated for $[\mathrm{MH}]^{+}$ $\mathrm{C}_{53} \mathrm{H}_{55} \mathrm{~N}_{2} \mathrm{~N}_{\mathrm{a}} \mathrm{O}_{8} \mathrm{~S}_{3}$ : 967.3096, found HRMS (TOFMS) $[\mathrm{MH}]^{+}$967.3066; low res (ESIMS) $[\mathrm{M}-\mathrm{Na}+2 \mathrm{H}]^{+}$: 948.5

Sodium-4-(2-((E)-2-((E)-2-((4-aminophenyl)thio) -3-((E)-2-(1,1-dimethyl-3-(4-sulfonatobutyl)-1H-benz o[e]indol-2(3H)-ylidene)ethylidene)cyclohex-1-en-1yl)vinyl)-1,1-dimethyl-1H-benzo[e]indol-3-ium-3-yl) butane-1-sulfonate (8): IR-820 (60 $\mathrm{mg})$ and 4-aminothiophenol (60 mg) was dissolved in dry DMF and stirred overnight. After DMF was removed by high vacuum, the residue was purified by chromatography using $\mathrm{MeOH} / \mathrm{CH}_{2} \mathrm{Cl}_{2}$ (1:3) as the elute solvent and 8 was obtained in $\sim 60 \%$ yield. UV-Vis: $830 \mathrm{~nm}$ (in $\mathrm{MeOH})(\varepsilon=207000) .{ }^{1} \mathrm{H}$ NMR $\left(400 \mathrm{MHz}, \mathrm{CDCl}_{3} \delta \mathrm{ppm}\right): 9.0$ (d, 2H, H-a), $8.2(\mathrm{~d}, 2 \mathrm{H}$, $\mathrm{H}-\mathrm{b}), 8.0(\mathrm{t}, 4 \mathrm{H}, \mathrm{H}-\mathrm{c}), 7.62(\mathrm{~d}, 4 \mathrm{H}, \mathrm{H}-\mathrm{d}), 7.48(2 \mathrm{~d}$ overlapped to be triplet, $2 \mathrm{H}, \mathrm{H}-\mathrm{e}), 7.12(\mathrm{~d}, 2 \mathrm{H}, \mathrm{H}-\mathrm{f})$, $6.70(\mathrm{~d}, 2 \mathrm{H}, \mathrm{H}-\mathrm{g}), 6.35(\mathrm{~d}, 2 \mathrm{H}, \mathrm{H}-\mathrm{h}), 4.30(\mathrm{t}, 4 \mathrm{H}, \mathrm{H}-\mathrm{i})$, $2.95(\mathrm{t}, 4 \mathrm{H}, \mathrm{H}-\mathrm{j}), 2.80(\mathrm{~m}, 4 \mathrm{H}, \mathrm{H}-\mathrm{k}), 2.00(\mathrm{~m}, 10 \mathrm{H}, 4 \mathrm{H}$ for $\mathrm{H}-\mathrm{l}, 6 \mathrm{H}$ for $\mathrm{m}, \mathrm{n}, \mathrm{o}), 1.90$ (s, 12H, H-p), 1.30 (s, H-q). MS calculated: $\mathrm{C}_{52} \mathrm{H}_{56} \mathrm{~N}_{3} \mathrm{~N}_{2} \mathrm{O}_{6} \mathrm{~S}_{3}$ : 937, Found: 937; HRMS calculated: $\mathrm{C}_{52} \mathrm{H}_{56} \mathrm{~N}_{3} \mathrm{~N}_{2} \mathrm{O}_{6} \mathrm{~S}_{3}$ : 937.3229, Found: $\mathrm{MH}^{+}, \mathrm{C}_{52} \mathrm{H}_{57} \mathrm{~N}_{3} \mathrm{~N}_{\mathrm{a}} \mathrm{O}_{6} \mathrm{~S}_{3} 938.3320$.

Sodium-4-((E)-2-((E)-2-(2-((4-aminophenyl)thio )-3-((E)-2-(3,3-dimethyl-1-(4-sulfonatobutyl)-3H-ind ol-1-ium-2-yl)vinyl)cyclohex-2-en-1-ylidene) ethylidene)-3,3-dimethylindolin-1-yl) butane-1-sulfonate (9) IR-783 (60 mg, $0.0716 \mathrm{mmol})$ and 4-aminothiophenol (75 mg, $0.479 \mathrm{mmol}$ ) was dissolved in dry DMF and stirred overnight. After DMF was removed by high vacuum, the residue was precipitated in ethyl ether purified by chromatography using $\mathrm{MeOH} / \mathrm{CH}_{2} \mathrm{Cl}_{2}$ (1:3) as the elute solvent and 9 was obtained in $\sim 80 \%$ yield. ${ }^{1} \mathrm{H}$ NMR $(400 \mathrm{MHz}$, $\mathrm{CDCl}_{3} \delta \mathrm{ppm}$ ): $8.84(\mathrm{~d}, 2 \mathrm{H}), 7.30-7.43$ (multiplets, $\left.6 \mathrm{H}\right)$, $7.22(\mathrm{t}, 2 \mathrm{H}), 7.01(\mathrm{~d}, 2 \mathrm{H}), 6.63(\mathrm{~d}, 2 \mathrm{H}), 6.30(\mathrm{~d}, 2 \mathrm{H}), 4.16$ $(\mathrm{t}, 4 \mathrm{H}), 2.87(\mathrm{t}, 4 \mathrm{H}), 2.75(\mathrm{t}, 4 \mathrm{H}), 1.90-2.00(\mathrm{~m}, 10 \mathrm{H}), 1.56$ $(\mathrm{s}, 12 \mathrm{H})$. ESIMS calculated: $\mathrm{C}_{44} \mathrm{H}_{52} \mathrm{~N}_{3} \mathrm{NaO}_{6} \mathrm{~S}_{3}$ : 838.0849, Found: 816.4; HRMS calculated $\mathrm{C}_{44} \mathrm{H}_{53} \mathrm{~N}_{3} \mathrm{O}_{6} \mathrm{~S}_{3}$ 816.1031, Found: 816.3150.

Sodium-4-((E)-2-((E)-2-(2-((3-carboxyphenyl)thi o)-3-((E)-2-(3,3-dimethyl-1-(4-sulfonatobutyl)-3H-in dol-1-ium-2-yl)vinyl)cyclohex-2-en-1-ylidene)ethyli dene)-3,3-dimethylindolin-1-yl)butane-1-sulfonate (10): IR-783 (50 mg, $0.0596 \mathrm{mmol})$ and 3-mercaptobenzoic acid (60 mg, $0.389 \mathrm{mmol}$ ) was dissolved in dry DMF and stirred overnight. After
DMF was removed by high vacuum, the residue was precipitated in ethyl ether purified by chromatography using $\mathrm{MeOH} / \mathrm{CH}_{2} \mathrm{Cl}_{2}$ (1:3) as the elute solvent and 10 was obtained in $\sim 80 \%$ yield. ${ }^{1} \mathrm{H}$ NMR (400MHz, $\left.\mathrm{CDCl}_{3} \delta \mathrm{ppm}\right): 8.77(\mathrm{~d}, 2 \mathrm{H}), 7.70-7.80$ $(\mathrm{m}, 2 \mathrm{H}), 7.45(\mathrm{~m}, 2 \mathrm{H}), 7.30-7.41$ (multiplets, $6 \mathrm{H}), 7.19$ $(\mathrm{t}, 2 \mathrm{H}), 6.34(\mathrm{~d}, 2 \mathrm{H}), 4.18(\mathrm{t}, 4 \mathrm{H}), 2.81-2.86(\mathrm{~m}, 8 \mathrm{H})$, $1.88-1.98(\mathrm{~m}, 10 \mathrm{H}), 1.46(\mathrm{~s}, 12 \mathrm{H})$. ESIMS calculated: $\mathrm{C}_{44} \mathrm{H}_{51} \mathrm{~N}_{2} \mathrm{NaO}_{8} \mathrm{~S}_{3}$ : 867.0798, Found: 889.3; HRMS $\mathrm{C}_{44} \mathrm{H}_{51} \mathrm{~N}_{2} \mathrm{NaO}_{8} \mathrm{~S}_{3}$ : Found: 867.2767.

\section{Results}

In an effort to prepare stable and suitably functionalized fluorophores with absorption and emission in the spectral range above $800 \mathrm{~nm}$, high molar extinction coefficients and reasonably high fluorescent quantum yields, several parent fluorophores, such as, commercially available ICG, IR820, IR783 (3) and adapted fluorophores, NIRFs 1, 2, 4, previously synthesized by Lucjan Strekowski's [16, 18], and NIRF 6 (otherwise known as Cypate) previously synthesized by Samuel Achilefu's [19, 20] groups, were screened for their fluoroscopic properties.

Once the evaluation of the above mentioned parent near infrared fluorophores (NIRFs) was complete we selected the better candidate(s) for further modification in order to develop improved bifunctional agents [15] for tumor-imaging (fluorescence) and PDT The synthesis of the suitably functionalized near infrared fluorophores (NIRFs) 5, 7-10, was performed under similar conditions, giving rise to predominantly green solids with yields above $50 \%$. These modified fluorophores 5, 7-10 were obtained upon functionalizing commercially available IR820 and IR783.

\section{Spectral Characterization}

All of the polymethine cyanine-based fluorophores ICG, IR820 and NIRFs 1-10, discussed herein, displayed long wavelength electronic absorption and emission bands with maxima in the range of $760-868$ nm (Table 1). Figures $\mathbf{1}-\mathbf{3}$ show the absorption and emission spectra and the structures of the studied fluorophores. All the photophysical properties of NIRFs 1-10 were investigated using $5 \mu \mathrm{M}$ solutions in methanol (Table 1) and $1 \mu \mathrm{M}$ solutions in Colon 26 complete media (RPMI), Table 2. The fluorescence spectra were acquired for each compound and the fluorescence quantum yields were determined by a comparing each spectrum with that of the indocyanine green (ICG), with known fluorescence quantum yield of 0.078 [21]. The obtained data suggested that compound 3 (commercially available IR783) could be the best candidate for conjugation to PS for further 
assessment, based on highest among the studied dyes absorptivity $\left(\varepsilon=261000 \mathrm{M}^{-1} \mathrm{~cm}^{-1}\right)$ and fluorescence efficiency $\left(\Phi_{\mathrm{Fl}}=0.084\right)$ (Table 1).

Table I: Electronic absorption and fluorescence characteristics of ICG, IR820 and other cyanine dyes I - I0. The Fluorescence quantum yields of NIR dyes were obtained in methanol $(5 \mu \mathrm{M})$ using ICG as a reference standard [2I]. All dyes were excited at $785 \mathrm{~nm}$.

\begin{tabular}{|c|c|c|c|c|c|}
\hline $\begin{array}{c}\text { NIR } \\
\text { Dyes }\end{array}$ & $\lambda_{\max }$ & $\lambda_{\mathrm{Em}_{\max }}$ & $\begin{array}{c}\text { Ext. Coeff. } \\
(\varepsilon)\end{array}$ & $\begin{array}{c}\text { Singlet Oxygen } \\
\text { Yield }\left(\Phi_{\Delta}\right)\end{array}$ & $\begin{array}{c}\text { Fluor. Quantum } \\
\text { Yield }\left(\Phi_{\mathrm{FI}}\right)\end{array}$ \\
\hline 1 & 784 & 804 & 190,000 & 0.007 & 0.057 \\
\hline 2 & 783 & 804 & 117,000 & 0.03 & 0.040 \\
\hline $\mathbf{3}$ & $\mathbf{7 8 2}$ & $\mathbf{8 1 0}$ & $\mathbf{2 6 1 , 0 0 0}$ & $\mathbf{0 . 0 0 7}$ & $\mathbf{0 . 0 8 4}$ \\
\hline 4 & 760 & 798 & 126,000 & 0.003 & 0.003 \\
\hline 5 & 834 & 868 & 197,000 & 0.012 & 0.030 \\
\hline 6 & 785 & 822 & 216,000 & 0.02 & 0.065 \\
\hline 7 & 832 & 866 & 207,000 & 0.02 & 0.035 \\
\hline 8 & 830 & 868 & 226,000 & 0.025 & 0.007 \\
\hline 9 & 795 & 829 & 187,000 & 0.02 & 0.006 \\
\hline 10 & 795 & 829 & 218,000 & 0.02 & 0.03 \\
\hline ICG & 785 & 822 & 204,000 & 0.008 & $0.07{ }^{*}$ \\
\hline IR820 & 820 & 850 & 202,000 & 0.02 & 0.044 \\
\hline
\end{tabular}

Table 2: Electronic absorption and fluorescence characteristics of ICG, IR820 and other cyanine dyes I - I0. The electronic absorption and fluorescence spectra of NIR dyes were obtained in Colon 26 complete media (RPMI) at (I $\mu \mathrm{M})$. All dyes were excited at $785 \mathrm{~nm}$.

\begin{tabular}{|c|c|c|}
\hline NIR Dyes & $\begin{array}{c}\lambda_{\max } \\
\text { (in Colon 26 Media) }\end{array}$ & $\begin{array}{c}\lambda_{\text {Em }_{\max }} \\
\text { (in Colon 26 Media) }\end{array}$ \\
\hline 1 & 784 & 801 \\
\hline 2 & 783 & 805 \\
\hline 3 & 782 & 807 \\
\hline 4 & 760 & 795 \\
\hline 5 & 834 & 869 \\
\hline 6 & 785 & 815 \\
\hline 7 & 832 & 869 \\
\hline 8 & 830 & 869 \\
\hline 9 & 795 & 827 \\
\hline 10 & 795 & 827 \\
\hline ICG & 785 & 801 \\
\hline IR820 & 820 & 857 \\
\hline & & \\
\hline
\end{tabular}
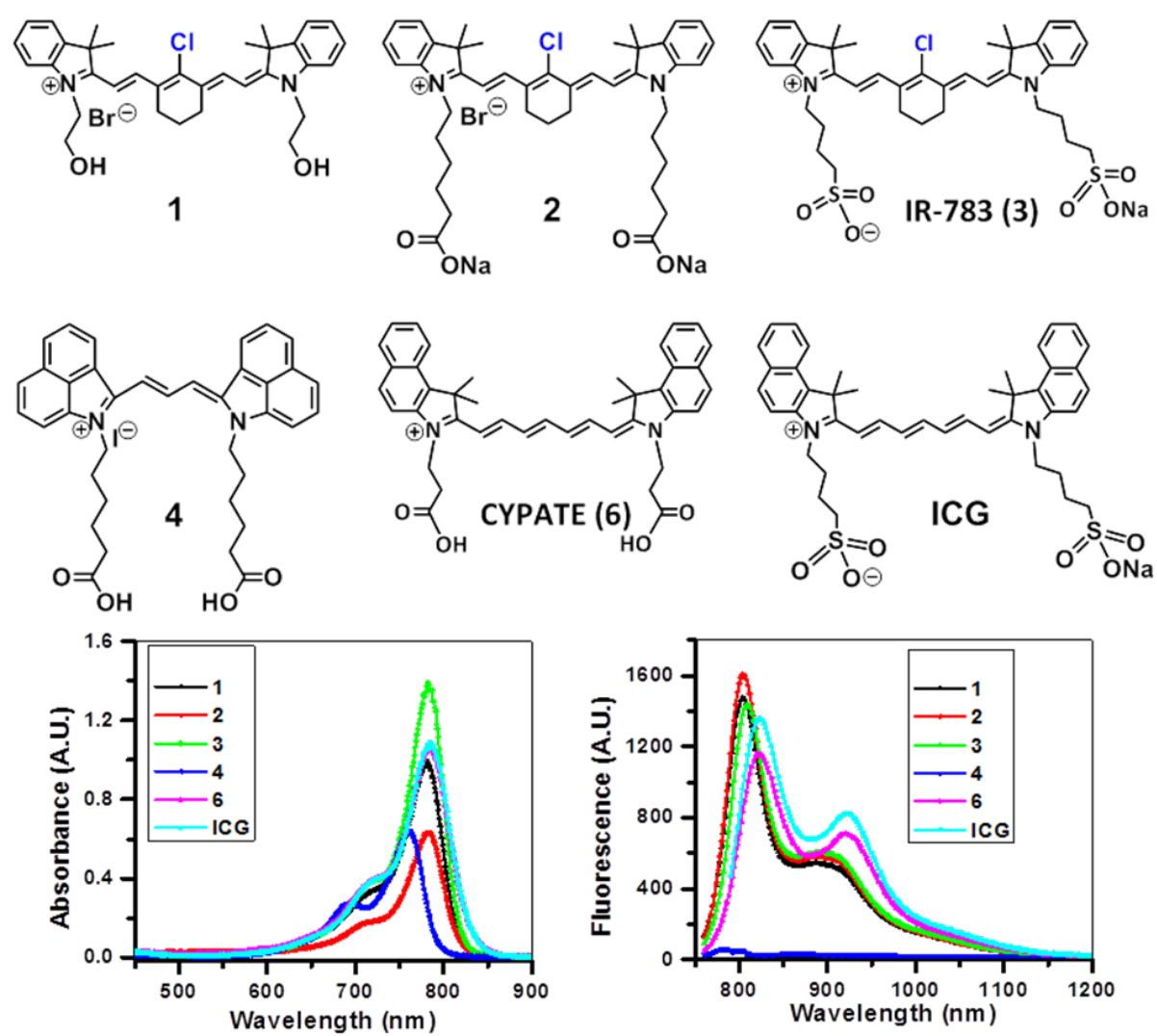

Figure I: Absorption (A), fluorescence (B) spectra of near infrared fluorophores (NIRFs) I-4 and ICG in methanol (5 $\mu \mathrm{M})$. 
<smiles>C/C=C/c1cccc(C(=O)O)c1Sc1cccc(C)c1</smiles>

7
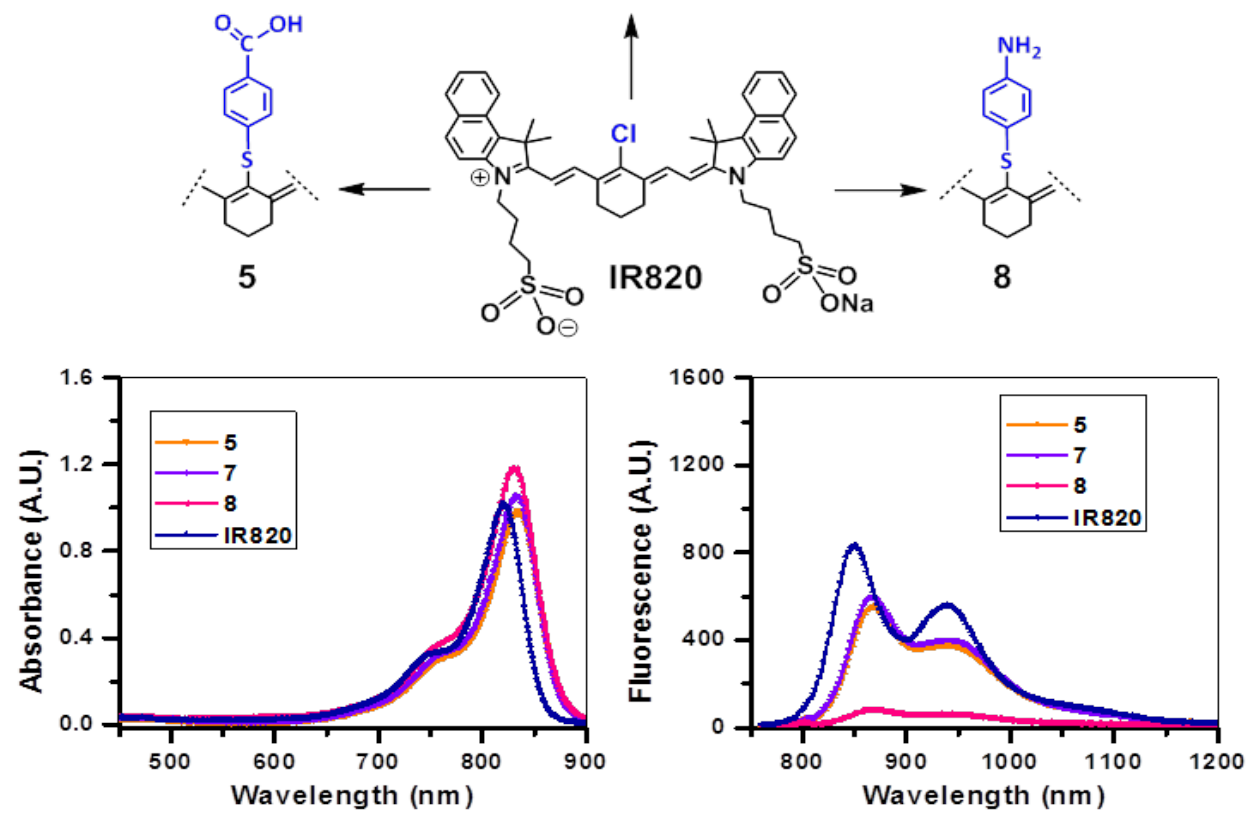

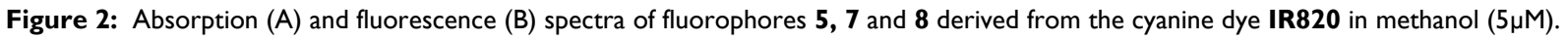
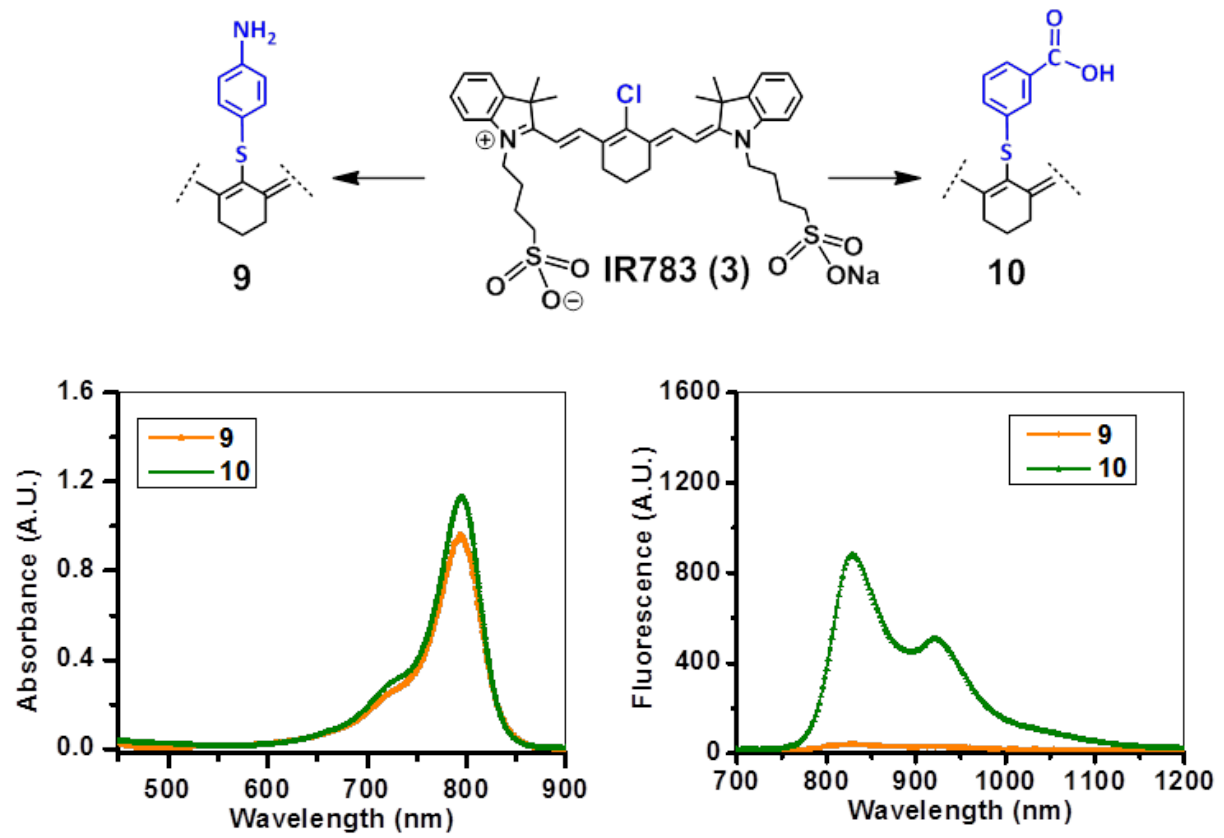

Figure 3: Absorbance (A) and fluorescence (B) spectra of fluorophores 9 and 10 derived from cyanine dye IR783 in methanol $(5 \mu \mathrm{M})$.

The excitation of ICG, IR820 and NIRFs 1-10 at $785 \mathrm{~nm}$ produced emission in the range of $798-868$ $\mathrm{nm}$ in methanol. All fluorophores exhibited Stokes shifts in the range of $20-40 \mathrm{~nm}$, Table 1 . However, when the fluorophores were excited in RPMI, Colon 26 media, the emission ranged from $795-869 \mathrm{~nm}$ with Stokes shifts ranging from $4-25 \mathrm{~nm}$, Table 2 . The singlet oxygen $\left({ }^{1} \mathrm{O}_{2}{ }^{*}\right)$ yields of all the fluorophores 
were also measured, using Rose Bengal as a reference $[22,23]$. From the photophysical data summarized in Table 1 it can be seen that among the NIRFs investigated compounds 4, 8 and 9 showed minimal fluorescence quantum yields and singlet oxygen yields.

The NIRFs containing indolenine nucleus, such as 1-3, 9 and 10, show similar absorbance and emission as that of NIRFs ICG and $\mathbf{6}$, bearing a benzindolenine moiety. The NIRF 4 possessing a fused benzindole group (Strekowski et al. unpublished results) also displayed absorbance and emission spectra observed for ICG and Cypate. The spectroscopic characteristics of NIRFs 5-8 were found to be close to their parent analogs IR820. ICG, 4 and 6, possessing a linear polymethine chain without a rigid cyclohexenyl moiety showed reduced photostability. It is worth noting that the introduction of an amino-terminated fragment in both IR820 and IR783 (3) reduced the fluorescence quantum yield of the parent analogs $\mathbf{8}$ and 9. These results were in contrast to the NIRFs 5, 7 and $\mathbf{1 0}$ containing carboxylic acid functionality (Figures 2,3 ).

Tumor uptake (in vitro): Cellular uptake was determined using flow cytometry with the modified Becton Dickinson FACScan and a single laser. Colon 26 and U87 cells were seeded as discussed above, in 6 well plates for $24 \mathrm{~h}$. The dyes were added at a concentration of $1 \mu \mathrm{M}$ and incubated for $24 \mathrm{~h}$.

Upon harvesting and preparing the single cell suspension in cold $2 \%$ FCS in PBS (FCM Buffer) they were analyzed. A single diode laser with an excitation at $785 \mathrm{~nm}$ and the $820 \mathrm{~nm}$ long pass (LP) emission filter were used to determine the NIR flow uptake of dyes ICG, IR820 and Compounds 1-10, in Colon 26 and U87 cells, Figure $4(\mathbf{A}, \mathbf{B})$. Since there is a difference in absorbance of dyes at 785 and their fluorescence response in the range above $820 \mathrm{~nm}$ is also different, the quantification of the cellular uptake, based on the raw flow cytometry data, is uncertain.

To resolve this issue, we have performed control experiment, measuring fluorescence of compounds suspended in cellular media with concentration of $1 \mu \mathrm{M}$ (i.e., conditions of cell treatment), using excitation with $785 \mathrm{~nm}$ laser diode. The acquired signal of fluorescence in the spectral range above 820 $\mathrm{nm}$ is presented in Figure $4(\mathrm{C}, \mathrm{D})$. Comparing difference between fluorescence from cells after cellular uptake (Figure 4A,B) with the initial fluorescence from cellular media (Figure 4C,D), one can estimate the cellular uptake of the investigated compounds in relation to each other.

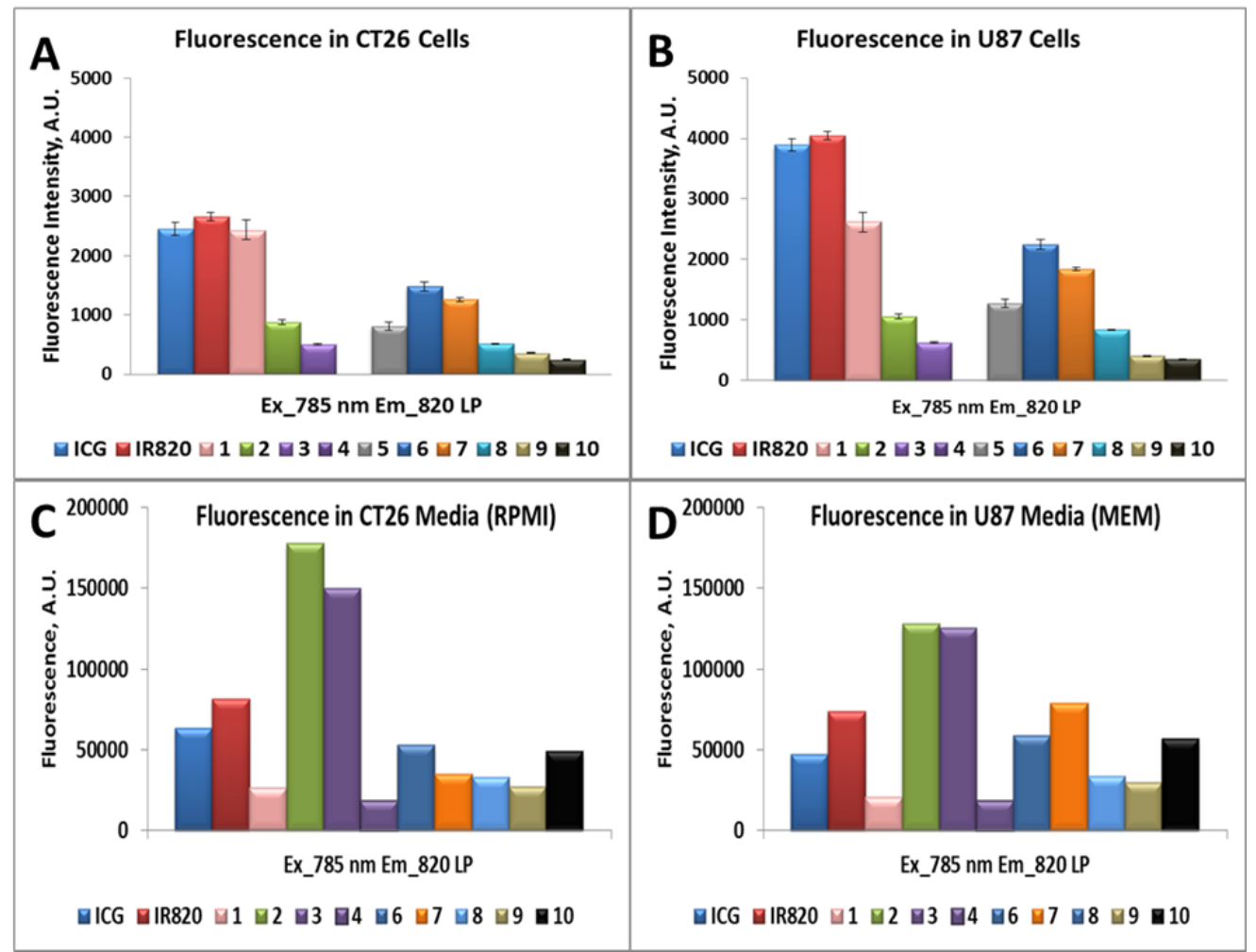

Figure 4: A single diode laser with an excitation at $785 \mathrm{~nm}$ and an emission at $820 \mathrm{~nm}$ long pass (LP) was used to determine the NIR flow uptake of dyes ICG, IR820, I-I 0, and $\mathbf{6}$ (cypate). Figures A and B presents the NIR flow uptake of the dyes (I $\mu \mathrm{M})$ in Colon 26 and U87 cells, whereas figures $\mathbf{C}$ and D illustrate the fluorescence of the dyes in Colon 26 and U87 media (RPMI and MEM) only. 
In vivo Imaging: $\mathrm{BALB} / \mathrm{c}$ mice bearing Colon 26 tumors on the right shoulder were injected intravenously (i.v.) with NIRFs 1-10, using a drug dose of $0.03 \mu \mathrm{mol} / \mathrm{kg}$. The whole body fluorescence images were obtained using a Maestro GNIR Flex In-vivo imaging system ( 3 mice / time point) at $24 \mathrm{~h}$ (as shown in Figs. 5-7) $48 \mathrm{~h}$ and $72 \mathrm{~h}$ post injection (p.i) followed by ex-vivo imaging of the organs from the same mice at the respective time points. A broadband excitation at $710-740 \mathrm{~nm}$ and $800 \mathrm{~nm}$ long pass emission was used to acquire the images. Ex vivo images were used to determine the semi-quantitative fluorescence biodistribution of the compounds in several organs. The fluorescence spectra of compounds 1-8 in the tumor, obtained with the Maestro system, are shown in Figs. 8A and 8B. The biodistribution of the tumor, skin and liver at various time points $(24-72 h)$ are shown in Figs. 8C and 8D.

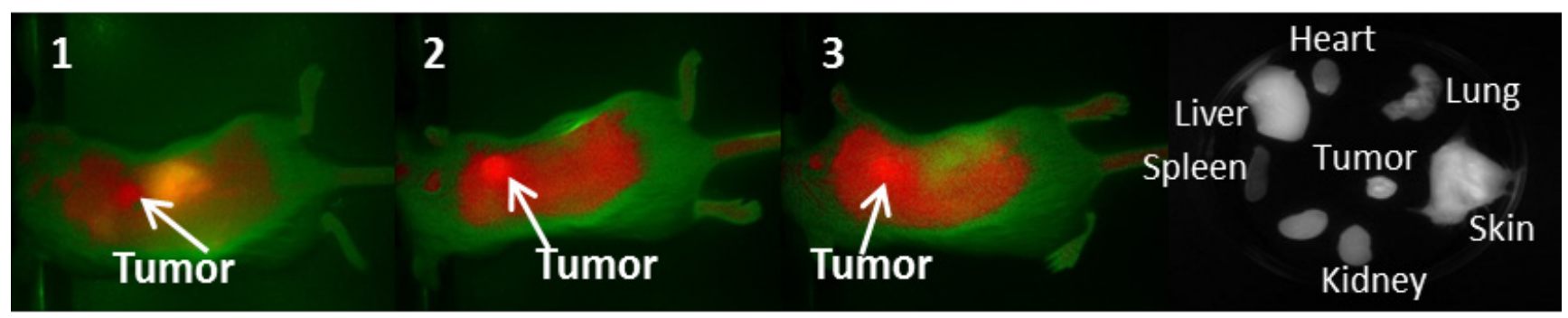

Figure 5: NIR whole body fluorescence images of BALB/c mice bearing Colon 26 tumors at $24 \mathrm{~h}$ post injection (p.i.) of the fluorophores I-3 (dose: $0.03 \mu \mathrm{mol} / \mathrm{kg}$ ). The ex vivo image of NIRF 3 at $24 \mathrm{~h}$ p.i is shown.

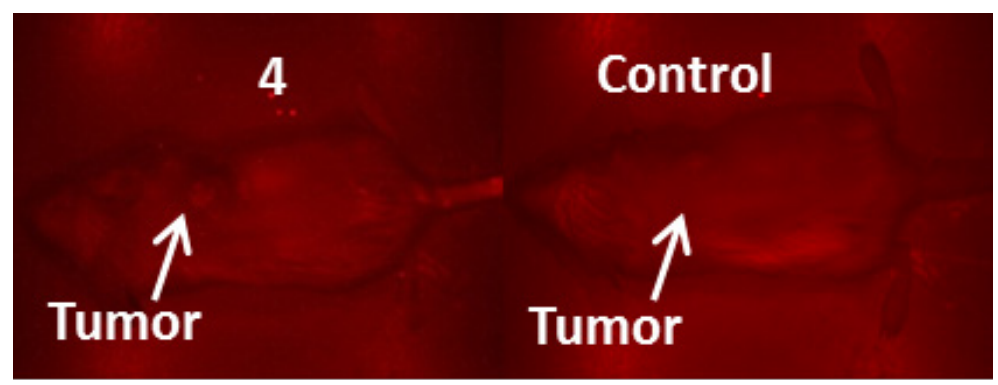

Figure 6: NIR Fluorescence images (no spectral unmixing) of BALB/c mice bearing Colon 26 tumors at 24 h post injection of a non-tumor avid cyanine dye 4 (dose: $0.03 \mu \mathrm{mol} / \mathrm{kg}$ ).

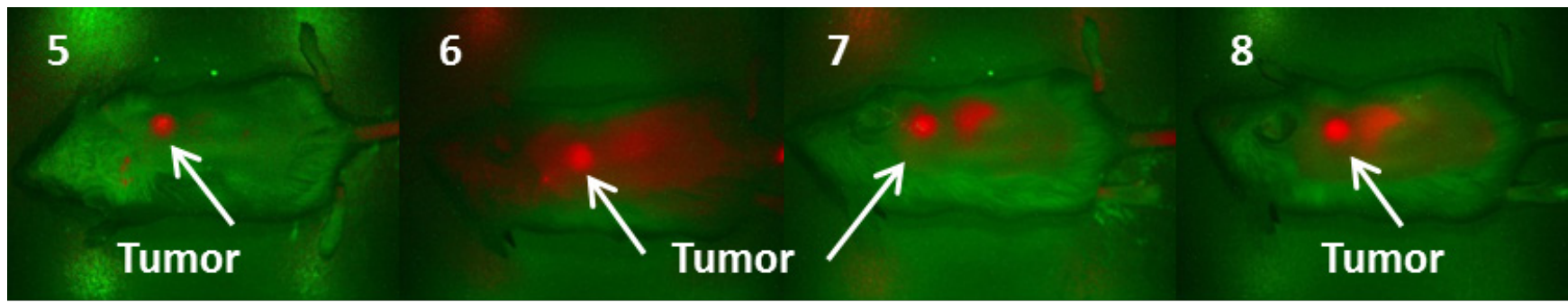

Figure 7: Fluorescence images of BALB/c mice bearing Colon 26 tumors at $24 \mathrm{~h}$ post injection of fluorophores 5-8 (dose: 0.03 $\mu \mathrm{mol} / \mathrm{kg}$ ). 


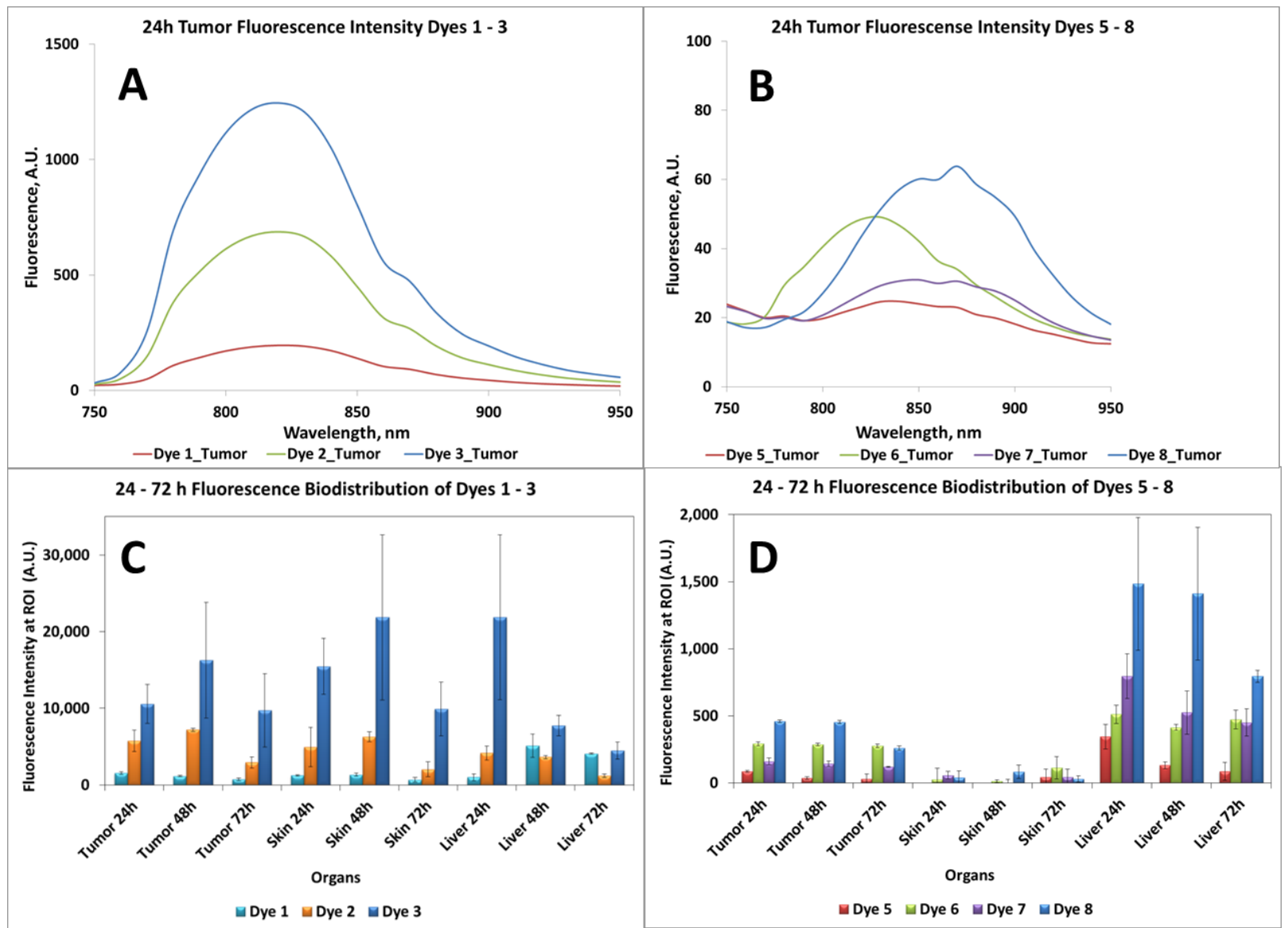

Figure 8: Ex vivo fluorescence biodistribution of NIRFs I-8. Note: The biodistribution of the cyanine dye 4 is not shown due to its weak in vivo fluorescence intensity.

\section{Discussion}

Based on the results shown in Figs. 8C and D, the tumor-fluorescence was approximately 10-fold intense for the NIRFs 1-3 than that observed for NIRFs 5-8. These results suggest that structural modification of the NIRFs by functionalizing with 4-aminothiophenol, 3-mercaptobenzoic and 4-mercaptobenzoic acid significantly decreases the tumor selectivity of NIRFs 5-10. Although, compounds 1-3 appeared to have significant uptake in the tumor when compared to 5-8, the uptake of compounds 1-3 in the skin and liver was also significant (Figs. 8C and 8D). Also, 5-8 seemed to have a high uptake in the liver over the ranges of $24-72 \mathrm{~h}$. This could be due to the fact that compounds 5-8 are being cleared rapidly from circulation by the liver due to the first pass effect [24, 25]. The liver is usually the primary route by which substances are metabolized and excreted. The fluorescence biodistribution of compounds 1-3 showed significant uptake in the tumor, skin, and the liver at $24-72 \mathrm{~h}$. Over time the quantity of drug remaining in each organ began to clear, but it was evident that 1-3 cleared from the liver more readily over time than they did from the tumor.

It is generally a challenge to deliver fluorophores selectively and in a high enough concentration to detect small tumors. It should be noted that compounds 2 and 3 showed enhanced tumor selectivity [26] compared to their counterparts; 3 showed the highest selectivity for the tumor within the series. The low fluorescent compound 4 was unsuitable as a fluorophore for fluorescence imaging. When the fluorescent images of 4 were compared to the control (non-injected tumored mice) no apparent difference between the two was observed (Figure 6).

The biodistribution of compounds 5-8, determined by the NIR fluorescence imaging, (Figure 8D) indicates that these compounds do accumulate more in tumor and the liver rather than the other organs. Accumulation in the skin, heart, lung, spleen and kidney are relatively low compared to that for compounds 1-3 (shown in supplementary materials). This also could, in part, be due to the rapid clearance of compounds 5-8 from these organs before imaging the mice at $24 \mathrm{hrs}$ post-injection. Compounds $\mathbf{9}$ and 10, the modified NIRFs of IR783 (3) showed reduced in vivo fluorescence imaging ability (data not shown). 
However, when conjugated to HPPH the fluorescence was very intense (discussed in the succeeding paper part-2 and shown in the supplemental section of part-2, pages 703 -718).

\section{Conclusion}

Among the cyanine dyes evaluated, compound 3 (IR783), the polymethine cyanine-based dye with the indolenine nucleus, a chlorinated cyclohexenyl center and a sulfonate group, was found to be the best candidate for NIR fluorescence tumor imaging in the series of NIRFs 1-5, 7-10, Cypate (6), ICG and IR820 probed for their absorbance/fluorescence properties. Although, NIRF 3 was the best both in terms of the spectral properties and tumor affinity, it would not be feasible to use it in the original form for our purposes. It needed further functionalization before conjugation to HPPH (3-(1'-hexyloxyethyl)pyropheophorbide-a), a highly effective photosensitizer undergoing Phase II human clinical trials [27]. In addition, cyanine dyes 5, 7-10 were synthesized from their parent IR820 and 3 (IR783) by replacing the central chlorinated cyclohexenyl group with 3-mercaptobenzoic acid (to yield 7 and 10), 4-mercaptobenzoic acid (to yield 5) and 4-aminophenol (to yield 8 and 9). Also, among the functionalized NIRFs (5, 7-10), the best structural substitute in terms of in vivo tumor uptake was found to be 4-aminothiophenol. At the same time, the photophysical data showed that the substitution with 4 -aminothiophenol caused quenching of the fluorescence in substituted NIRFs $\mathbf{8}$ and 9. Based on the results reported in this study, further studies were performed: the NIRFs 5, 7, 8, 9 and 10 were conjugated with HPPH in the mono and di-forms. See the succeeding paper (Part-2, pages 703 - 718). NIRFs 5 and 7 were used to assess whether the position of the dye with respect to HPPH within the conjugate made a difference in PDT response.

There should be noticeable difference between the pharmacokinetic properties of the cyanine dyes versus the corresponding cyanine dye-photosensitizer conjugates. Therefore, for our studies, we selected a series of dyes for further conjugation to our photosensitizer, not specifically on the basis of their tumor selectivity, but mainly due to their comparative stability and photophysical properties. Considering that most of the cyanine dyes, in general do not selectively accumulate in tumor tissue, the idea was to take the advantages of tumor-avid PDT agents as vehicles to deliver the desired fluorophores to the tumor site and investigate the utility of the corresponding conjugates for imaging large and deeply seated tumors with an option of photodynamic therapy.

\section{Supplementary Materials}

Ex vivo fluorescence biodistribution of near infrared fluorophores (NIRFs) 1-3 and 5-8 at 24, 48 and $72 \mathrm{~h}$ postinjection. The ${ }^{1} \mathrm{H}$ NMR spectra of NIRFS 5 and 7-10. http://www.thno.org/v03p0692s1.pdf

\section{Abbreviations}

NIR: near infrared; NIRF: near infrared fluorophore; PDT: Photodynamic therapy; CD: Cyanine dye.

\section{Acknowledgement}

The authors are highly thankful to NIH for financial support (NIH:RO1CA127369), research supplement to promote diversity in health-related research to Nadine S. James (RO1 CA127369S) and program project grant (PO1CA55791). Mass spectrometry analyses of the compounds were performed at the Michigan State University, East Lansing, Michigan and the University at Buffalo, Buffalo, NY, 14263.

\section{Competing Interests}

The authors have declared that no competing interest exists.

\section{References}

1. Chen X, Conti PS, Moats RA. In vivo Near-Infrared Fluorescence Imaging of Integrin av $\beta 3$ in Brain Tumor Xenografts. Cancer Res. 2004; 64: 8009-14

2. Chen $\mathrm{Y}$, Zheng $\mathrm{G}$, Zhang $\mathrm{ZH}$, Blessington $\mathrm{D}$, Zhang $\mathrm{M}$, Li H, et al. Metabolism-enhanced tumor localization by fluorescence imaging: in vivo animal studies. Opt Lett FIELD Full Journal Title:Optics letters. 2003; 28: 2070-2.

3. Graves EE, Weissleder R, Ntziachristos V. Fluorescence molecular imaging of small animal tumor models. Current Molecular Medicine. 2004; 4: 419-30

4. Moon WK, Lin Y, O'Loughlin T, Tang Y, Kim D-E, Weissleder R, et al. Enhanced tumor detection using a folate receptor-targeted near-infrared fluorochrome conjugate. Bioconjugate Chem. 2003; 14: 539-45.

5. Ntziachristos V, Ripoll J, Wang LV, Weissleder R. Looking and listening to light: the evolution of whole-body photonic imaging. Nature Biotechnology. 2005; 23: 313-20.

6. Tung C-H, Lin Y, Moon WK, Weissleder R. A receptor-targeted near-infrared fluorescence probe for in vivo tumor imaging. ChemBioChem. 2002; 3: 784-6.

7. Veiseh M, Gabikian P, Bahrami SB, Veiseh O, Zhang M, Hackman RC, et al. Tumor Paint: A Chlorotoxin:Cy5.5 Bioconjugate for Intraoperative Visualization of Cancer Foci. Cancer Res. 2007; 67: 6882-8.

8. Bouteiller C, Clave G, Bernardin A, Chipon B, Massonneau M, Renard P-Y, et al. Novel Water-Soluble Near-Infrared Cyanine Dyes: Synthesis, Spectral Properties, and Use in the Preparation of Internally Quenched Fluorescent Probes. Bioconjugate Chem. 2007; 18: 1303-17.

9. Weissleder $R$, Ntziachristos V. Shedding light onto live molecular targets. Nature Medicine (New York, NY, United States). 2003; 9: 123-8.

10. Kaijzel EL, van dPG, Lowik CWGM. Whole-body optical imaging in animal models to assess cancer development and progression. Clin Cancer Res. 2007; 13: 3490-7.

11. Achilefu S, Dorshow RB, Bugaj JE, Rajagopalan R. Novel receptor-targeted fluorescent contrast agents for in vivo tumor imaging. Investigative Radiology. 2000; 35: 479-85.

12. Jiang F-L, Poon C-T, Wong W-K, Koon H-K, Mak N-K, Choi CY, et al. An amphiphilic bisporphyrin and its YbIII complex: development of a bifunctional photodynamic therapeutic and near-infrared tumor-imaging agent. ChemBioChem. 2008; 9: 1034-9. 
13. Zheng G, Chen Y, Intes X, Chance B, Glickson JD. Contrast-enhanced near-infrared (NIR) optical imaging for subsurface cancer detection. J Porphyrins Phthalocyanines. 2004; 8: 1106-17. doi:10.1142/s1088424604000477.

14. Strekowski L. Heterocyclic Polymethine Dyes; Synthesis, Properties and Applications. [In: Top. Heterocycl. Chem., 2008; 14]: Springer GmbH; 2008.

15. Chen Y, Gryshuk A, Achilefu S, Ohulchansky T, Potter W, Zhong T, et al. A Novel Approach to a Bifunctional Photosensitizer for Tumor Imaging and Phototherapy. Bioconjugate Chem. 2005; 16: 1264-74.

16. Narayanan N, Patonay G. A New Method for the Synthesis of Heptamethine Cyanine Dyes: Synthesis of New Near-Infrared Fluorescent Labels. J Org Chem. 1995; 60: 2391-5. doi:10.1021/jo00113a018.

17. Strekowski L, Lipowska M, Patonay G. Substitution reactions of a nucleofugal group in heptamethine cyanine dyes. Synthesis of an isothiocyanato derivative for labeling of proteins with a near-infrared chromophore. J Org Chem. 1992; 57: 4578-80. doi:10.1021/jo00043a009.

18. Strekowski L, Mason CJ, Lee H, Gupta R, Sowell J, Patonay G. Synthesis of water-soluble near-infrared cyanine dyes functionalized with [(succinimido)oxy]carbonyl group. J Heterocycl Chem. 2003; 40: 913-6. doi:10.1002/jhet.5570400527.

19. Ye Y, Bloch S, Kao J, Achilefu S. Multivalent Carbocyanine Molecular Probes: Synthesis and Applications. Bioconjugate Chem. 2005; 16: 51-61.

20. Zhang Z, Achilefu S. Synthesis and evaluation of polyhydroxylated near-infrared carbocyanine molecular probes. Org Lett. 2004; 6: 2067-70.

21. Benson RC, Kues HA. Fluorescence properties of indocyanine green as related to angiography. Physics in Medicine \& Biology. 1978; 23: 159-63. doi:10.1088/0031-9155/23/1/017.

22. Demas JN, Harris EW, McBride RP. Energy transfer from luminescent transition metal complexes to oxygen. J Am Chem Soc. 1977; 99: 3547-51. doi:10.1021/ja00453a001.

23. Ohulchanskyy TY, Roy I, Goswami LN, Chen Y, Bergey EJ, Pandey RK, et al. Organically Modified Silica Nanoparticles with Covalently Incorporated Photosensitizer for Photodynamic Therapy of Cancer. Nano Lett. 2007; 7: 2835-42.

24. Silverman RB. The Organic Chemistry of Drug Design and Drug Action. Burlington, USA: Elsevier Academic Press; 2004.

25. Thomas G. Fundamentals of Medicinal Chemistry. New York, USA: John Wiley \& Sons Ltd; 2003.

26. Yang $X$, Shi $C$, Tong $R$, Qian $W$, Zhau HE, Wang $R$, et al. Near IR Heptamethine Cyanine Dye-Mediated Cancer Imaging. Clinical Cancer Research. 2010; 16: 2833-44. doi:10.1158/1078-0432.ccr-10-0059.

27. Nava HR, Allamaneni SS, Dougherty TJ, Cooper MT, Tan W, Wilding G, et al. Photodynamic therapy (PDT) using HPPH for the treatment of precancerous lesions associated with Barrett's esophagus. Lasers Surg Med. 2011; 43: 705-12. 